\title{
A vocalização da consoante lateral em coda silábica em uma variedade de português brasileiro: análise sociolinguística em tempo real
}

Elisa Battisti ${ }^{a}$

Viviane Tebaldi Moras ${ }^{b}$

\begin{abstract}
Resumo
A análise de regra variável em tempo real (LABOV, 1972, 1994) da vocalização da consoante lateral ///em coda silábica (canal cana[w], Brasil Brasi[w]) no português falado em Flores da Cunha (RS) revelou progresso na aplicação da regra entre 1990 e 2008-2009. O incremento na vocalização acompanhou mudanças econômicas e sociais ocorridas no pequeno município, fundado por imigrantes italianos no final do século XIX. O grupo etário jovem mostrou-se condicionador da aplicação da regra, o sexo/gênero feminino completou a aquisição da forma vocalizada. No contexto fonológico seguinte, a tendência a vocalizar passou a ser exercida pelas consoantes altas e vogais posteriores, além das consoantes labiais. Em relação à tonicidade da sílaba, o processo deixou de ter o efeito da sílaba tônica para ser afetado apenas por sílaba átona. A proporção total de vocalização passou de $12 \%$ em 1990 a 77\% em 2008-2009. O aumento expressivo na aplicação da regra acompanhou o aumento da população urbana e da realização de atividades econômicas nessa área, reduzindo o falar dialetal italiano e seu contato com o português, o que poderia ter refreado a vocalização.
\end{abstract}

Palavras-chave: Variação linguística, Português brasileiro, Vocalização da lateral em coda silábica, Análise em tempo real.

Recebido em 13 de novembro de 2015 Aceito em 05 de março de 2016

\footnotetext{
a Professora Adjunta do Departamento de Linguística, Filologia e Teoria Literária do Instituto de Letras da UFRGS, battisti.elisa@gmail.com

${ }^{\mathrm{b}}$ Bolsista de Iniciação Científica PIBIC/CNPq, graduanda em Letras Português e Literaturas na UFRGS, vtmoras@gmail.com
} 
Vocalização é o processo fonológico pelo qual uma consoante é transformada em vogal ou semivogal quando ocupa certas posições da sílaba ou da palavra. A motivação do processo é em geral prosódica, como ocorre no português brasileiro com a consoante lateral /1/ em coda silábica (ou posição pós-vocálica), esteja a sílaba no interior ou em final de vocábulo: falta fa[w]ta, futebol futebo[w], móvel móve[w], almoço a[w]moço.

Processo bastante difundido no português brasileiro (PINHO e MARGOTTI, 2010; CARDOSO et.al., 2014), aplica-se em proporções diversas em falares do interior do estado do Rio Grande do Sul, contribuindo para distinguir variedades regionais. Este artigo trata da vocalização variável da lateral em coda silábica no município gaúcho de Flores da Cunha, cujo falar representa o de comunidades onde houve ou ainda há contato entre o português e falares dialetais italianos. A realização alveolar da lateral (fa[l]ta, futebol[l], móve[l], a[l]moço) caracteriza o português de contato. A realização vocalizada é a variante inovadora, resultante da aplicação do processo conforme a tendência geral do português brasileiro.

O objetivo do trabalho é captar o padrão de variação e mudança linguística na comunidade. A hipótese a ser testada, decorrente de resultados bastante distintos obtidos em estudos anteriores com dados da mesma comunidade (TASCA, 1999; BATTISTI e MORAS, no prelo), é a de que a vocalização da lateral em coda silábica tenha sido implementada e sofrido rápido incremento em vinte anos, num processo progressivo de variação e mudança linguística que acompanhou alterações sócio-econômicas na comunidade.

Fundamentado na Teoria da Variação de Labov (1972), o presente estudo guia-se pela ideia de que a heterogeneidade linguística verificada na fala seja sistemática, resultante da aplicação de regras variáveis. Capta a sistematicidade quantitativamente, com análise estatística de dados, medindo os efeitos da interação de grupos de fatores linguísticos e sociais sobre o processo investigado. A principal contribuição do trabalho está em realizar tal análise em tempo real (LABOV, 1994), isto é, com dados coletados na mesma comunidade em dois períodos distintos, num intervalo de quase vinte anos entre uma e outra coleta. As análises anteriores foram 
realizadas em tempo aparente, com dados coletados num só período, contando apenas com o exame do comportamento de diferentes grupos etários frente à regra para verificar a existência de variação na mudança em progresso. Além disso, os dados serão tratados com os mesmos procedimentos analíticos, eliminando a possibilidade de que diferenças significativas nos índices de vocalização da lateral em um e outro período derivem de desenhos de análise distintos.

$\mathrm{O}$ artigo inicia-se pela fundamentação teórica em fonologia e em sociolinguística variacionista. Seguem a revisão da literatura, a metodologia e a apresentação e discussão dos resultados. Por fim, vem a conclusão do trabalho.

\section{Fundamentação teórica}

\subsection{Vocalização da lateral}

Em termos fonéticos, laterais são descritas como sons da fala em cuja articulação a parte frontal da língua eleva-se, interpondo-se no centro na cavidade oral e levando a corrente de ar egressiva a escapar por um ou pelos dois lados da língua (ASHBY, 2011).

No sistema fonológico do português, há dois tipos de consoantes laterais. Ambas podem ocorrer em posição de onset silábico, isto é, antes da vogal: /1/, que apresenta uma articulação dental ou alveolar, correspondendo à lateral alveolar (lua, sala), e $/ K /$, que se articula na região posterior ou palatal, correspondendo à lateral palatal (folha). Já em coda silábica (após a vogal) ocorre apenas uma consoante lateral, que não se manifesta propriamente como alveolar, mas alveolar velarizada. O resultado é uma articulação velarizada ou inteiramente velar. Se houver a supressão da elevação da ponta da língua junto aos dentes ou alvéolos e também o arredondamento dos lábios, ocorre a alteração chamada vocalização:

“[...] Daí decorre uma mutação, que em linguística diacrônica se chama a 'vocalização' da consoante: cessa a elevação da ponta da língua junto aos dentes, a elevação posterior do dorso da língua não chega a interromper a corrente de ar e há um concomitante leve arredondamento dos lábios". (CÂMARA JR., 1977, p. 41) 
Collischonn (2014, p. 90) explica que essa mutação enfraquece a consoante. O segmento enfraquecido é percebido como próximo de $[\mathrm{w}]$ pelos falantes que, por essa razão, passam a realizar o vocoide em lugar da consoante.

As alterações articulatórias e perceptuais associadas à vocalização da lateral são motivadas prosodicamente. Devem-se ao fato de a consoante ocupar coda silábica, posição que, conforme Goldsmith (1990), é licenciador secundário, licencia menos contrastes do que o onset. O português limita a coda a glide, líquidas (segmentos que não contrastam por ponto de articulação), /s/ ou nasal homorgânica à consoante seguinte, evidência de que coda não licencia traço de ponto de articulação, apenas onset tem essa capacidade. Sem traço de ponto de articulação de consoante, a lateral em coda tende a manifestar-se como $[w]$, segmento que, além de ser articulatoriamente similar à lateral, como se viu acima, é uma aproximante menos marcada do que as coronais na hierarquia de ponto de articulação (De LACY, 2006, p.128).

Na vocalização da lateral, portanto, as manifestações fonéticas são desencadeadas por restrições linguísticas ou estruturais. Já a difusão do processo no português brasileiro e os diferentes padrões de variação relacionam-se a aspectos sociais peculiares às comunidades de fala.

\subsection{Variação linguística e comunidade de fala}

Labov (1972, p.158) afirma que "uma comunidade de fala não pode ser concebida como um grupo de falantes que usam, todos, as mesmas formas; é melhor definida como um grupo que partilha as mesmas normas em relação à língua". A análise sociolinguística variacionista busca explicitar as normas de uso das variantes. Verifica as variáveis linguísticas e sociais condicionadoras do uso numa dada comunidade de fala.

Variáveis linguísticas dizem respeito a restrições estruturais que sustentam o processo, como posição da sílaba na palavra, tonicidade da sílaba, contexto fonológico precedente e seguinte. Variáveis sociais contemplam a organização social da comunidade em grupos etários, classes sociais, gêneros, locais de residência, graus de escolaridade, por exemplo. Não o indivíduo, mas a comunidade de fala, abrangida por essas 
variáveis, tem papel primordial na análise variacionista, como afirma o próprio Labov (1994) ao caracterizar sua pesquisa:

"a comunidade de fala, não o idioleto, é o objeto primeiro da investigação linguística. [...] o falante individual só pode ser entendido como o produto de uma história social única e da intersecção de padrões linguísticos de todos os grupos e categorias sociais que definem esse indivíduo. [...] os indivíduos não são as unidades finais da análise linguística, mas os componentes que são usados para construir modelos de nosso objeto primeiro de interesse, a comunidade de fala." (LABOV, 1994, p.34)

O estudo da variação linguística nessa perspectiva situa a investigação no nível coletivo e implica admitir que as comunidades são linguística e sócio-historicamente definidas. As comunidades fazem progredir a variação e mudança linguística, na transmissão da língua de uma geração a outra. Em termos analíticos, esse progresso pode ser captado em tempo real se o pesquisador dispuser de amostras de fala da comunidade coletadas em diferentes períodos de tempo e puder comparar os índices de aplicação das regras variáveis longitudinalmente, em um e outro período. Se, no entanto, o pesquisador dispuser de amostra de fala coletada num só momento, pode captar o progresso em tempo aparente, comparando as proporções de aplicação da regra em diferentes grupos etários, representantes de gerações de falantes pertencentes à comunidade. $\mathrm{O}$ fato de os grupos etários mais jovens empregarem mais a forma inovadora do que os mais idosos revela a tendência de a regra progredir na comunidade.

Ambos os desenhos de pesquisa, tempo real e tempo aparente, assumem a hipótese laboviana de que nosso sistema fonológico está definido na juventude e é relativamente estável na vida adulta. É o que Labov (1994, p.83) chama de pressuposto da mudança geracional (generational change, em inglês). Se há inovação linguística pela variação, ela ocorre no período de aquisição da linguagem, pelo incremento dos efeitos dos condicionadores do padrão de fala da comunidade. O resultado são mudanças graduais, com aumentos sutis no uso das formas inovadoras a cada geração. Comportamentos desviantes desse padrão - incremento abrupto na proporção total de uso de uma dada variante pela comunidade ou por um dado grupo etário, por exemplo - devem-se a mudanças na comunidade que afetam estilos de vida, interação dos indivíduos e, consequentemente, 
${ }^{1}$ VARSUL, ou Variação Linguística na Região Sul do Brasil, é um acervo de entrevistas sociolinguísticas com informantes de diferentes sexos/gêneros, níveis de escolaridade e idades, residentes nas capitais e algumas cidades do interior dos três estados do Sul do Brasil, Rio Grande do Sul, Santa Catarina e Paraná. As entrevistas de sua amostra-base foram realizadas no início dos anos 1990. O acervo é mantido pela PUCRS, UFRGS, UFSC, UFPR. padrões de uso linguístico. Urbanização, êxodo rural, aumento da escolaridade, desenvolvimento de novos setores econômicos estão entre as alterações sócio-econômicas que podem ter impacto nas normas de uso partilhadas na comunidade de fala, como se verá neste estudo.

\section{Revisão de literatura}

A realização variável da lateral em coda silábica no português do sul do Brasil foi objeto de várias análises. Revisamos aqui três delas, de Quednau (1993), Tasca (1999), Battisti e Moras (no prelo), todas realizadas em tempo aparente. Uma das comunidades investigadas por Quednau (1993) é similar a Flores da Cunha, de base étnica italiana. As análises de Tasca (1999) e Battisti e Moras (no prelo) usam dados da própria Flores da Cunha, mas de amostras diferentes. Os resultados dessas análises fundamentam as variáveis controladas no presente estudo e estão na base de suas questões-problema, enunciadas na Metodologia.

Quednau (1993) analisa a fala de 60 informantes distribuídos em quatro regiões geográficas do Rio Grande do Sul: metropolitana (Porto Alegre), fronteiriça (representada pela cidade de Santana do Livramento, zona de contato português-espanhol), de colonização alemã (representada pelo município de Taquara) e de colonização italiana (representada pela localidade de Monte Bérico, distrito de Veranópolis). O corpus foi coletado em 1981 por Leda Bisol, para sua tese de doutorado, e hoje integra o acervo VARSUL ${ }^{1}$. Utilizando a vocalização da lateral como variável dependente, Quednau (1993) encontra uma proporção total de $45 \%$ de aplicação da regra, com a seguinte distribuição: 91\% em Porto Alegre, 27\% em Santana do Livramento, 23\% em Monte Bérico e 20\% em Taquara. Verifica que a vocalização é favorecida pelos metropolitanos e desfavorecida tanto pelos fronteiriços, quanto pelos descendentes de italianos e alemães. As variáveis sociais Idade e Sexo mostram-se inexpressivas, mas o acento tônico e pretônico, as vogais médias anteriores e posteriores como contexto fonológico precedente, consoantes altas como contexto seguinte e a lateral em composições e sufixos especiais -mente e -zinho favorecem a aplicação da regra. 
Tasca (1999) analisa dados de fala de quatro comunidades de descendentes de imigrantes do Rio Grande do Sul, a partir de vinte entrevistas cada, realizadas no início dos anos 1990 e integrantes do banco de dados VARSUL. As comunidades são a capital do estado, Porto Alegre (descendentes de açorianos); no interior, Flores da Cunha (descendentes de italianos), Panambi (descendentes de alemães) e São Borja (fronteiriços, em contato com o espanhol). Por não ter encontrado indícios de vocalização no interior, Tasca investiga a alternância entre lateral velarizada e vocalização em Porto Alegre, e a alternância entre lateral alveolar e lateral velarizada em comunidades do interior do estado. Na capital, a proporção de ocorrência de lateral velarizada é de $54 \%$. Homens, indivíduos maiores de 50 anos e informantes do nível primário favorecem a realização da lateral velarizada em Porto Alegre, assim como palavras em que a lateral ocupa posição final ou interior de palavra simples e posição tônica. Já nas comunidades do interior, a proporção de ocorrência da lateral alveolar em Flores da Cunha e Panambi é de $71 \%$ e $77 \%$, respectivamente, enquanto em São Borja é de $24 \%$. Como em Porto Alegre, os homens, informantes maiores de 50 anos e do nível primário condicionam o emprego da lateral alveolar; a lateral em posição final ou interior de palavra simples e os contextos que possuem lateral em posição tônica também favorecem a realização alveolar.

Battisti e Moras (no prelo) analisam a vocalização variável da lateral em coda silábica em apenas um dos municípios situados na antiga região colonial italiana do Rio Grande do Sul (RCI-RS), Flores da Cunha. Usam dados do BDSer ${ }^{2}$, coletados em 2008 e 2009. Examinam contextos de aplicação levantados de

2 BDSer, ou Banco de Dados de Fala da Serra Gaúcha, é um acervo de entrevistas sociolinguísticas realizadas de 2001 a 2009, de informantes de diferentes sexos/gêneros, níveis de escolaridade, idades, locais de residência, habitantes de quatro municípios da antiga região colonial italiana do Rio Grande do Sul (RCI-RS). Esse acervo é mantido pela UCS. 48 entrevistas sociolinguísticas. Diferentemente de Tasca (1999), as autoras verificam que há vocalização da lateral no português falado na comunidade, e numa proporção total expressiva: $72 \%$ de aplicação da regra. Todas as variáveis controladas - idade, local de residência, sexo/gênero, tonicidade da sílaba, contexto fonológico precedente e seguinte, posição da sílaba na palavra - têm efeito sobre o processo. Favorecem a vocalização da lateral os jovens da zona urbana e do sexo/gênero feminino, as sílabas átonas pretônica e postônica, a vogal alta posterior no contexto fonológico precedente, as consoantes alta, labial e 
alveolar no contexto fonológico seguinte, a lateral em interior de palavra. A análise mostra, portanto, que o processo tende a progredir na comunidade.

Os resultados das três análises, principalmente nas proporções totais de aplicação verificadas, são paradoxais. O estudo de Quednau (1993) verifica vocalização da lateral pósvocálica em comunidades do interior gaúcho já na década de 1980, mesmo que em proporções baixas - Monte Bérico, de base étnica italiana, apresenta $23 \%$ de vocalização. O estudo de Tasca (1999), no entanto, verifica apenas realização consonantal da lateral no interior gaúcho nos anos 1990. Não constata, portanto, vocalização da lateral em Flores da Cunha. Mais tarde, Battisti e Moras (no prelo) verificam $72 \%$ de vocalização da lateral nessa comunidade nos anos 2008 e 2009. Além da possibilidade de as proporções contrastantes derivarem de diferenças analíticas, a revisão das três análises em tempo aparente parece sugerir que a vocalização da lateral pós-vocálica foi implementada em Flores da Cunha nos anos 1990 e a partir de então sofreu rápido incremento. Vêm daí as questões-problema deste artigo, a serem respondidas com o reexame de dados do VARSUL e do BDSer, agora em tempo real.

\section{Metodologia}

\subsection{Questões-problema de pesquisa}

(a) Há aplicação da regra de vocalização da lateral em coda silábica em Flores da Cunha nos anos 1990, mesmo que mínima?

(b) Há progressão da regra nos últimos vinte anos? Se sim, em que proporção?

(c) Que fatores sociais e linguísticos condicionam a vocalização da lateral?

(d) Que aspectos sócio-históricos e econômicos relacionam-se ao padrão de vocalização variável em Flores da Cunha? 


\subsection{A comunidade de fala}

Flores da Cunha é um dos 55 municípios situados na antiga RCI-RS, região do estado do Rio Grande do Sul em que se fundaram colônias de imigrantes italianos no final do século XIX. Flores da Cunha possui cerca de 27 mil habitantes (IBGE, 2015), distribuídos em uma área de $272,66 \mathrm{~km}^{2}$.

Figura 1 - Flores da Cunha no Rio Grande do Sul e no Brasil
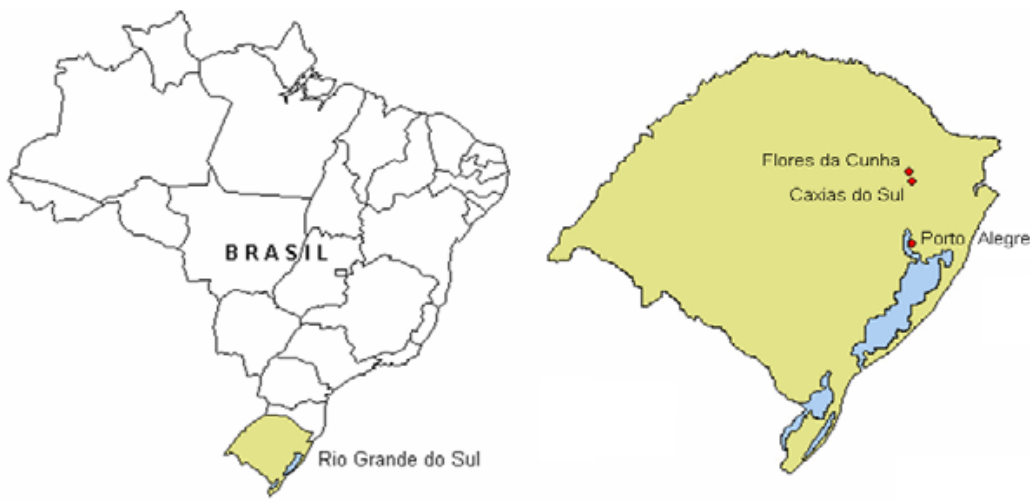

Fonte: As autoras

O município localiza-se no nordeste do estado. Pequeno em termos populacionais e territoriais, faz limite com Caxias do Sul, maior cidade do interior do estado, a que os florenses têm acesso frequente, beneficiando-se de comércio, serviços e opções de lazer.

A economia do município é diversificada. A zona rural abriga pequenas e médias propriedades em que núcleos familiares cultivam hortifrutigranjeiros e criam aves, porcos, gado e vacas leiteiras. A zona urbana conta com estabelecimentos comerciais e de serviços. Em sua periferia estão os estabelecimentos industriais, dedicados principalmente à produção de móveis, vinhos e suco de uva.

A economia de Flores da Cunha inclui também o setor de turismo, que se beneficia de ações e leis municipais de valorização das raízes italianas. Além de promover celebrações como a Festa da Vindima, possui em seu calendário o Dia da Etnia e do Dialeto Italiano (20 de maio, data da chegada dos imigrantes italianos à área onde hoje se situa a cidade). As práticas bilíngues, sobretudo orais (falar e compreender 
a língua), verificam-se na zona rural. Na zona urbana, predominam as práticas linguísticas monolíngues-português. Fomentar o falar dialetal italiano é hoje um dos objetivos de um projeto municipal voltado ao resgate da cultura e trajetória de desenvolvimento da cidade.

Uma repercussão linguística dessas ações poderia ser a valorização do português com marcas de contato com o falar dialetal italiano, entre elas a realização alveolar não-velarizada da lateral. A realização consonantal da lateral gozaria, assim, de prestígio encoberto (covert prestige, LABOV, 1972), com o significado social de solidariedade à cultura local. No entanto, nosso convívio na comunidade de Flores da Cunha para a realização das entrevistas sociolinguísticas não revelou que a variante lateral alveolar tivesse tal prestígio, tampouco que a variante vocalizada gozasse de prestígio aberto (overt prestige), como pode ocorrer com formas supra-locais veiculadas pela escola, mídia e usadas por grupos de maior status social. Não houve comentários metalinguísticos às formas por nós empregadas (somos sujeitos vocalizadores), tampouco gestos, expressões ou pistas interacionais reveladoras de prestígio das alternantes em variação, as formas vocalizada e não-vocalizada. A aplicação da regra de vocalização da lateral em coda silábica parece se dar, portanto, abaixo do nível da consciência.

\subsection{A análise}

A análise em tempo real, com dados de fala de entrevistas realizadas em períodos distintos, pode ser de dois tipos, de painel ou de tendência (LABOV, 1994). No estudo de painel, as entrevistas são feitas com os mesmos informantes, contatados novamente após alguns anos. No de tendência, as entrevistas são com informantes diferentes, mas de mesmo perfil social, considerando-se a estratificação da amostra. É análise em tempo real, estudo de tendência, o que se faz no presente artigo.

As entrevistas sociolinguísticas de informantes de Flores da Cunha de que se levantaram os dados para a análise em tempo real pertencem a dois acervos, o banco de dados VARSUL (1990) e o BDSer (2008-2009), que têm critérios diferentes de estratificação. O VARSUL tem suas entrevistas distribuídas em sexo (masculino e feminino), idade (menos de 50 anos e mais de 50 anos) e escolaridade (primário, secundário e ginásio). 
O BDSer, em gênero (masculino e feminino), faixa etária (18 a 29 anos, 30 a 49 anos, 50 a 69 anos e 70 anos ou mais anos), local de residência (zona urbana e zona rural) e escolaridade (primário, fundamental, médio, superior). Para compatibilizar critérios e obter uma amostra homogênea, desconsideraramse variáveis (local de residência e escolaridade) e, a partir da idade declarada no momento da entrevista, identificaram-se em cada acervo 12 informantes distribuídos equilibradamente em três grupos etários ( 25 a 39 anos, 40 a 59 anos, 60 ou mais anos) e dois sexos/gêneros (masculino e feminino).

Os contextos de vocalização da lateral, num total de 1248 do VARSUL e 918 do BDSer, foram levantados de oitiva das entrevistas sociolinguísticas. Dados de trechos pouco audíveis foram desprezados. Casos duvidosos, em que não se possuía certeza da realização vocálica ou consonantal da lateral, foram analisados acusticamente com o software Praat (BOERSMA e WEENINK, 2013), num total de 54 ocorrências.

Os dados levantados das entrevistas foram codificados conforme a variável dependente, vocalização da lateral em coda silábica (almoço a [w]moço, futebol futebo[w]), registrandose aplicação ou não da regra. Depois, foram codificados conforme as variáveis independentes linguísticas contexto fonológico precedente, contexto fonológico seguinte, tonicidade da sílaba, posição da lateral, e as variáveis independentes extralinguísticas sexo/gênero e idade. O Quadro 1, a seguir, reúne as variáveis independentes.

Quadro 1 - Variáveis independentes

\begin{tabular}{|c|c|}
\hline Variáveis linguísticas & $\begin{array}{c}\text { Variáveis extra- } \\
\text { linguísticas }\end{array}$ \\
\hline $\begin{array}{l}\text { Contexto fonológico precedente } \\
\text { Vogal baixa: hospital, almoço } \\
\text { Vogal média-baixa anterior: papêl, aluguêl } \\
\text { Vogal média-alta anterior: maleávell, horrívẹl } \\
\text { Vogal alta anterior: difícill, humillde } \\
\text { Vogal média baixa posterior: futeboll, lençol } \\
\text { Vogal média-alta posterior: volltar, moldura } \\
\text { Vogal alta posterior: faculdade, última }\end{array}$ & $\begin{array}{l}\text { Sexo/Gênero } \\
\text { Feminino } \\
\text { Masculino }\end{array}$ \\
\hline
\end{tabular}




\begin{tabular}{|c|c|}
\hline Variáveis linguísticas & $\begin{array}{c}\text { Variáveis extra- } \\
\text { linguísticas }\end{array}$ \\
\hline 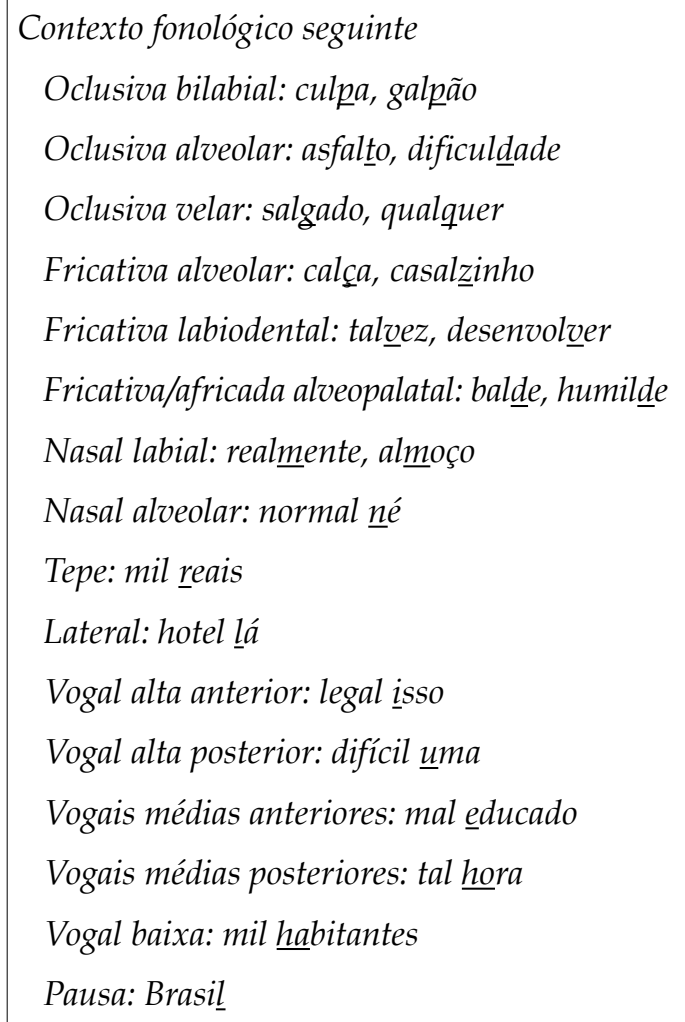 & $\begin{array}{l}\text { Idade } \\
25-39 \text { anos } \\
40-59 \text { anos } \\
60 \text { ou mais anos }\end{array}$ \\
\hline $\begin{array}{l}\text { Tonicidade da sílaba } \\
\text { Tônica: parreiral, adulto } \\
\text { Pretônica: faculdade, cultura } \\
\text { Postônica: difícil, agradável } \\
\text { Monossílabo: tal, mal }\end{array}$ & \\
\hline $\begin{array}{l}\text { Posição da lateral } \\
\text { Interior de palavra: folga, voḷta } \\
\text { Final de palavra não derivada: anel, Brasil } \\
\text { Final de palavra derivada: razoável, pessoal } \\
\text { Final de morfema no interior da palavra: } \\
\text { realmente, humildade }\end{array}$ & \\
\hline
\end{tabular}

O controle dessas variáveis testou as hipóteses de que a vocalização seja condicionada pelas vogais baixa e alta posterior no contexto precedente, por consoantes altas no contexto seguinte, pelas sílabas átonas, pela lateral em interior de palavra, pelos jovens do sexo/gênero feminino. 
Depois de codificados, os dados foram submetidos ao programa computacional Rbrul (JOHNSON, 2015) para análise estatística. Os dados de cada banco foram rodados separadamente, mas com o mesmo conjunto de variáveis independentes. Obtiveram-se a proporção total de aplicação e a proporção de aplicação por fator das variáveis controladas, apresentadas em porcentagens. Obtiveram-se também pesos relativos no intervalo de zero a um - valores abaixo de 0,5 indicam que o fator não condiciona a regra, valores acima de 0,5 indicam que o fator é condicionador, valores em torno de 0,5 indicam que o fator é neutro.

Numa etapa complementar, realizou-se pesquisa bibliográfica sobre elementos sócio-econômicos de Flores da Cunha e análise de conteúdo das entrevistas sociolinguísticas, em busca de elementos com base em que se pudesse discutir os resultados obtidos na análise estatística (quantitativa).

\section{Apresentação e discussão dos resultados}

A análise quantitativa dos dados de fala de Flores da Cunha - 1248 levantados de entrevistas do VARSUL e 918 de entrevistas do BDSer - mostrou não só que havia vocalização da lateral em coda silábica nos anos 1990, como também que o processo teve incremento expressivo em vinte anos. É o que revelam as proporções totais de aplicação da regra: $12 \%$ nos dados do VARSUL (1990), 77\% nos dados do BDSer (20082009). Como veremos a seguir, o controle da variável idade nos dados do VARSUL aponta a tendência de a aplicação da regra progredir na comunidade. $\mathrm{O}$ que surpreende é a proporção verificada em 2008-2009, que parece contrariar a ideia de a variação e mudança progredirem gradativamente, de geração a geração. Forças sociais além das articulatório-estruturais devem ter dirigido o processo em Flores da Cunha, ao promover o contato entre a variedade local e outras variedades de português brasileiro a partir de que a forma inovadora se difundiu. É a ideia a ser explorada aqui. Antes, no entanto, apresentam-se os resultados das variáveis controladas na análise.

Foi necessária a amalgamação de fatores em algumas variáveis (contexto fonológico precedente, contexto fonológico seguinte e posição da lateral), buscando-se uma boa distribuição de dados em cada fator. 
$\mathrm{Na}$ rodada com os dados de entrevistas do BDSer, o programa selecionou todas as variáveis exceto posição da lateral. Na rodada com dados do VARSUL, idade, contexto fonológico seguinte e tonicidade da sílaba foram selecionadas. Apresentam-se apenas os resultados das variáveis que se mostraram significativas nos dois bancos.

\subsection{Variáveis extralinguísticas}

\subsubsection{Idade}

O exame dos dados confirma a hipótese de que o grupo etário jovem condiciona a vocalização, tanto em 1990 (VARSUL) quanto em 2008-2009 (BDSer), como se vê na Fig.2.

Figura 2 - Idade

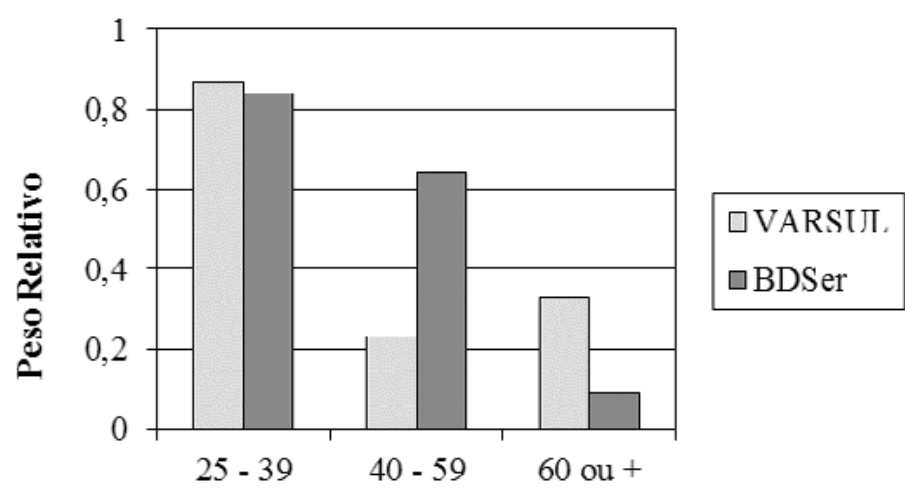

Os efeitos de idade na amostra mais recente (BDSer 2008-2009) são monotônicos e gradientes: os grupos etários 25-39 anos e 40-59 anos favorecem a vocalização da lateral em coda silábica, com destaque para o primeiro. O grupo 60 ou mais anos desfavorece o processo. Os pesos relativos revelam aumento na tendência a vocalizar a cada nova geração, o que caracteriza processos variáveis na mudança em progresso. Já os efeitos de idade na amostra de 1990 (VARSUL) são distintos: o grupo etário 25-39 anos condiciona a vocalização, os demais grupos desfavorecem. É o padrão de um processo inovador que ingressa na comunidade na fala dos mais jovens e não afeta as gerações precedentes. 
O cruzamento dos resultados da variável idade com os da variável sexo/gênero auxilia a compreender os diferentes efeitos de idade nos dois períodos. A Fig.3 traz os resultados referentes à amostra de 1990 (VARSUL) e a Fig.4, à de 2008-2009 (BDSer).

Figura 3 - Cruzamento de Idade e Gênero, dados de 1990 (VARSUL)

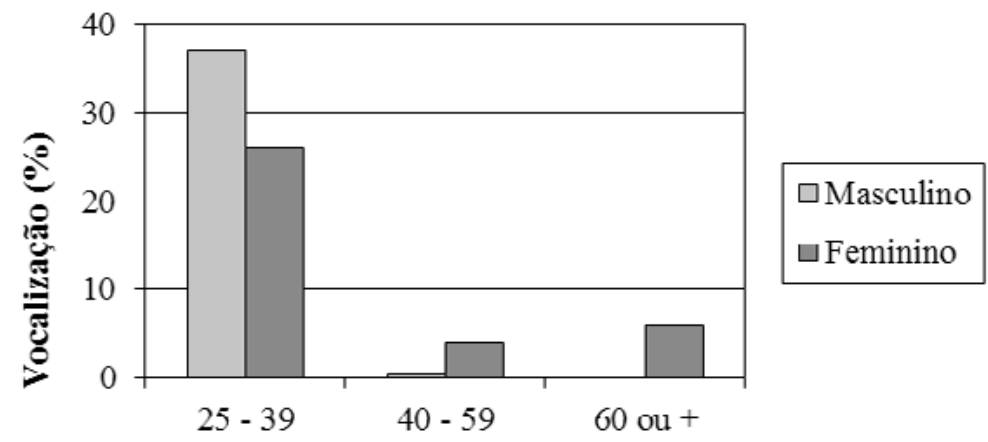

Figura 4 - Cruzamento de Idade e Gênero, dados de 2008-2009 (BDSer)

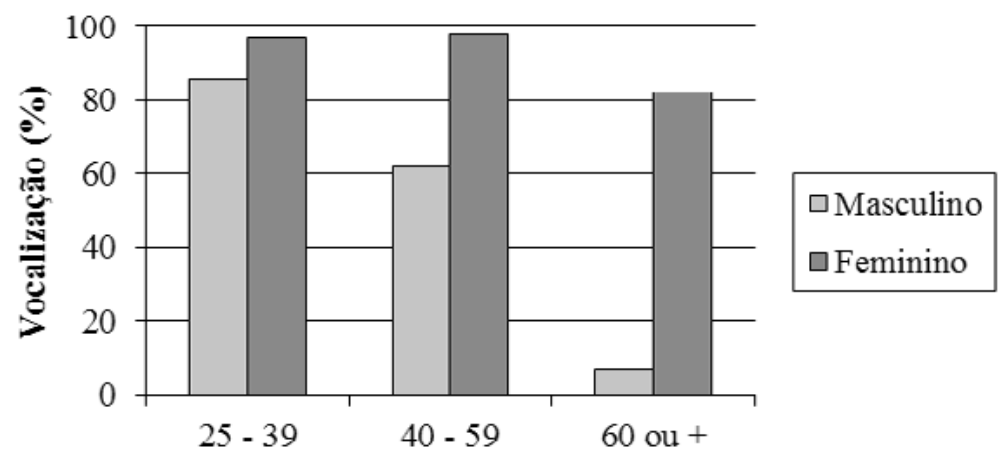

Na amostra de 1990 (VARSUL), além de as proporções de vocalização serem baixas nos grupos etários 40-59 anos e 60 ou mais anos, são praticamente exclusivas ao sexo/gênero feminino. Mas no grupo 25-39 anos são superiores para masculino, embora as proporções sejam significativas para ambos os sexos/gêneros.

Na amostra de 2008-2009 (BDSer), o padrão muda consideravelmente: o sexo/gênero feminino supera o 
masculino em todos os grupos etários. Apresenta proporção alta de vocalização da lateral já no grupo 60 ou mais anos e a proporção (próxima a 100\%) nos outros dois grupos é de aplicação categórica da regra. O sexo/gênero masculino, por seu turno, apresenta baixa vocalização no grupo 60 ou mais anos, mas a proporção aumenta significativamente no grupo 40-59 anos e é acima de 80\% no grupo 25-39 anos, aproximandose da proporção do sexo/gênero feminino.

O cruzamento dos resultados da variável idade com os da variável sexo/gênero mostra, portanto, que feminino está à frente de masculino em todos os grupos etários de ambas as amostras, exceto no dos jovens de 1990, o que talvez se explique por práticas e papeis sociais específicos a jovens do sexo/gênero masculino naquele período. Além disso, na amostra mais recente (BDSer 2008-2009), os resultados revelam que jovens do sexo/gênero feminino já completaram a aquisição da forma vocalizada. O progresso na vocalização variável da lateral em coda por jovens vem sendo promovido, mais recentemente, pelo sexo/gênero masculino.

\subsection{Variáveis linguísticas}

\subsubsection{Contexto fonológico seguinte}

A análise confirma a hipótese de que consoantes altas seguintes condicionam a vocalização, mas apenas na amostra de 2008-2009 (BDSer), como se vê na Fig.5.

Figura 5 - Contexto fonológico seguinte

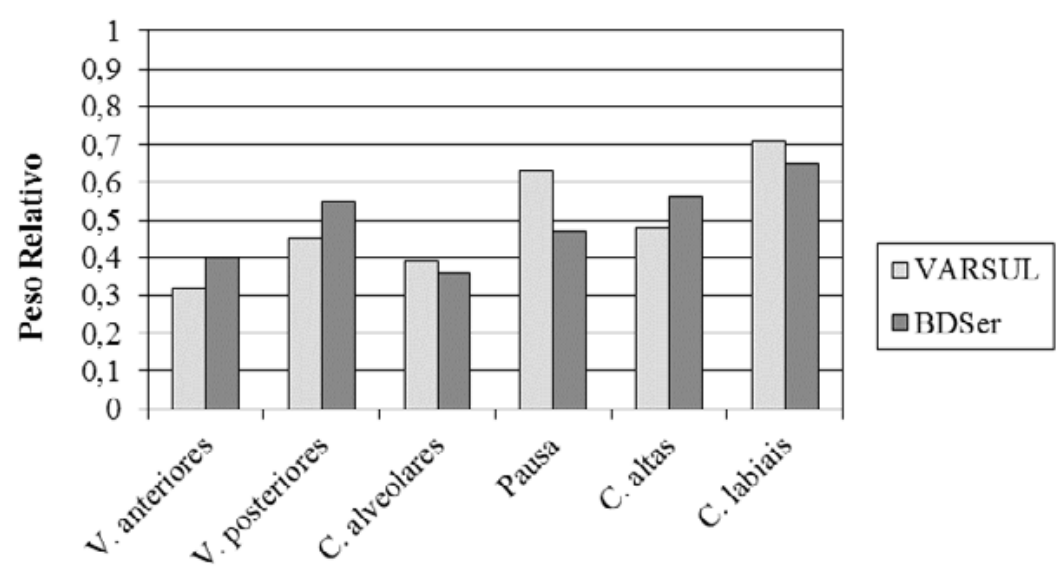


Na amostra de 1990 (VARSUL), a vocalização da lateral tende a ocorrer em pausa (ou contexto fonológico seguinte vazio) ou no contexto de consoante labial seguinte. Isso revela que o condicionamento prosódico em si e, eventualmente, um traço comum com o alvo [w] (labialidade) condicionam a aplicação da regra. Já na amostra de 2008-2009 (BDSer), a vocalização da lateral em coda tende a se verificar quando a consoante é seguida de vogais posteriores, consoantes labiais e altas, segmentos que compartilham traços com o alvo [w] (labialidade, posterioridade, altura). A análise revela, portanto, que o efeito fonotático sobre a vocalização aumentou com o progresso da regra na comunidade.

\subsubsection{Tonicidade da sílaba}

A expectativa de que sílabas átonas condicionassem a vocalização confirmou-se no fator Pretônica nos dois períodos, 1990 (VARSUL) e 2008-2009 (BDSer). Nos demais fatores, as tendências são discrepantes. Observe-se a Fig.6.

Figura 6 - Tonicidade da sílaba

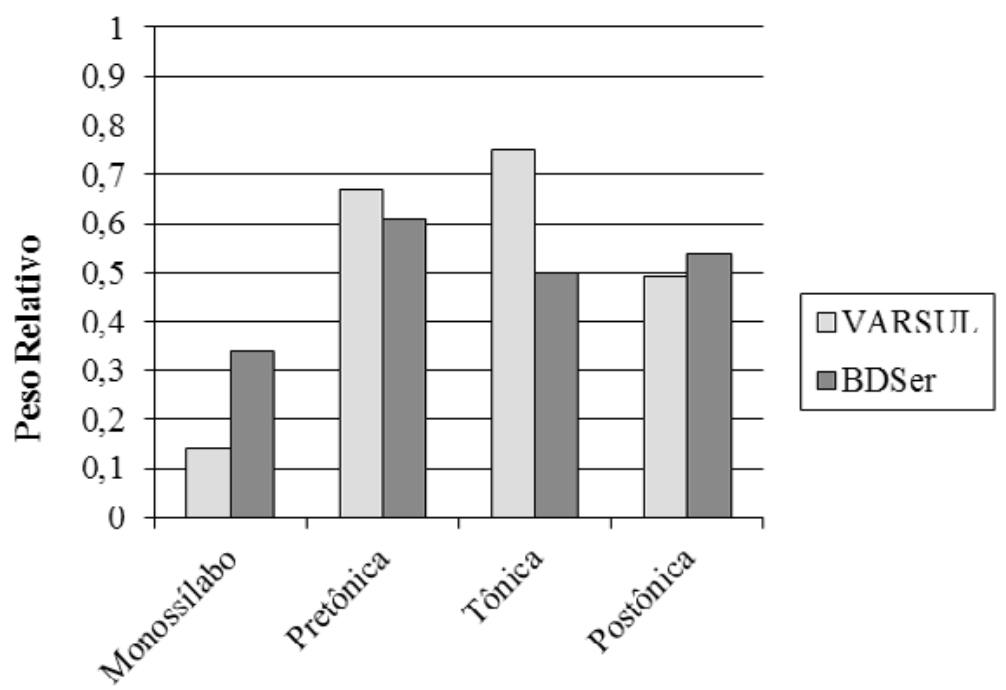

Enquanto em 1990 (VARSUL) o processo tende a ocorrer em sílabas pretônicas e tônicas, em 2008-2009 (BDSer) 
apenas as sílabas pretônicas se destacam. Isso parece sugerir que o progresso da vocalização esteja associado à menor proeminência da sílaba na palavra, ambiente de menor saliência fônica, propício ao enfraquecimento consonantal.

Os resultados da análise em tempo real para as variáveis sociais e linguísticas mostram mudanças no padrão de vocalização da lateral em coda silábica na comunidade de Flores da Cunha, de um estágio inicial a outro em que a regra alcança progresso significativo. Fatores sociais e linguísticos interagem no condicionamento da regra. É possível afirmar que em 2008-2009 a vocalização é categórica na fala de mulheres jovens e expressiva na de homens jovens, e que o processo, inicialmente (1990) com pouco efeito fonotático, passível de afetar a lateral também em sílaba tônica, exibe em 2008-2009 efeitos de segmentos seguintes com propriedades similares ao segmento-alvo e tende a afetar a lateral em sílabas prosodicamente fracas.

A proporção total de vocalização de $12 \%$ em Flores da Cunha em 1990 é baixa e sugere que o resultado de Tasca (1999) - inexistência de vocalização - para dados da mesma fonte, entrevistas do VARSUL, derive de diferenças em procedimentos analíticos, como a seleção de entrevistas e a codificação dos dados.

A proporção total de aplicação de 77\% em 2008-2009 é alta, considerando-se o tempo decorrido (vinte anos). Se esse índice fosse em torno de $30 \%$, expressaria o incremento gradativo que se espera verificar geracionalmente, em decorrência do processo de aquisição da linguagem. A proporção verificada sugere que forças sociais além de idade e gênero, mas atuando sobre essas variáveis, estejam dirigindo a vocalização da lateral em coda silábica em Flores da Cunha, acompanhando mudanças na comunidade. Que alterações tiveram lugar em Flores da Cunha no período de abrangência deste estudo, de 1990 a 2008-2009?

A consulta a fontes bibliográficas como Oliveira (1992) e dados sócio-econômicos e demográficos disponibilizados pelo IBGE mostra incremento das atividades econômicas desenvolvidas na zona urbana, como também da população nessa área (Figs. 7 e 8). 
Figura 7 - Alguns setores econômicos em Flores da Cunha

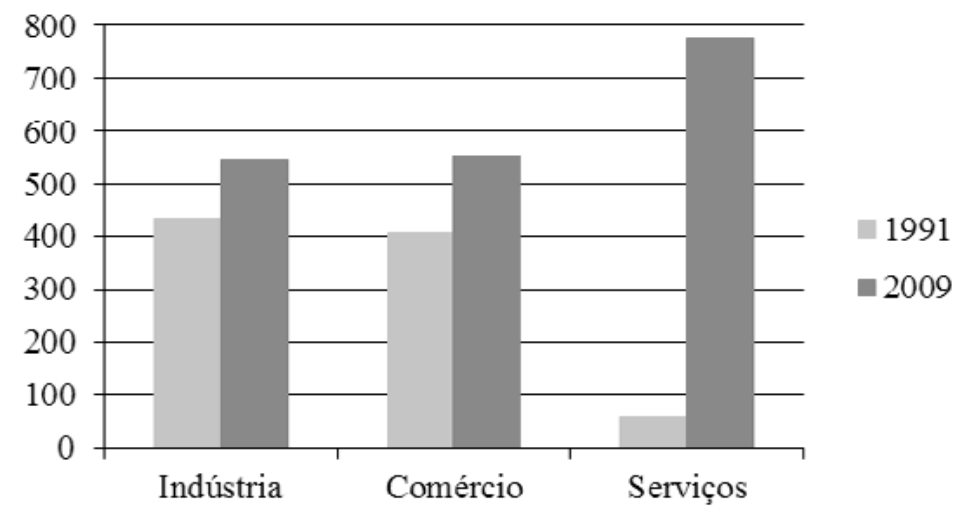

Fonte: As autoras, com base em Oliveira (1992) e IBGE (2015).

Em 1991, estavam registradas em Flores da Cunha 901 empresas, distribuídas entre indústria, comércio e serviços. Em 2009, 1.893 empresas estavam registradas, com um aumento significativo no setor de serviços, muito provavelmente incrementado pelo aumento da densidade populacional urbana.

Figura 8 - Número de habitantes de Flores da Cunha

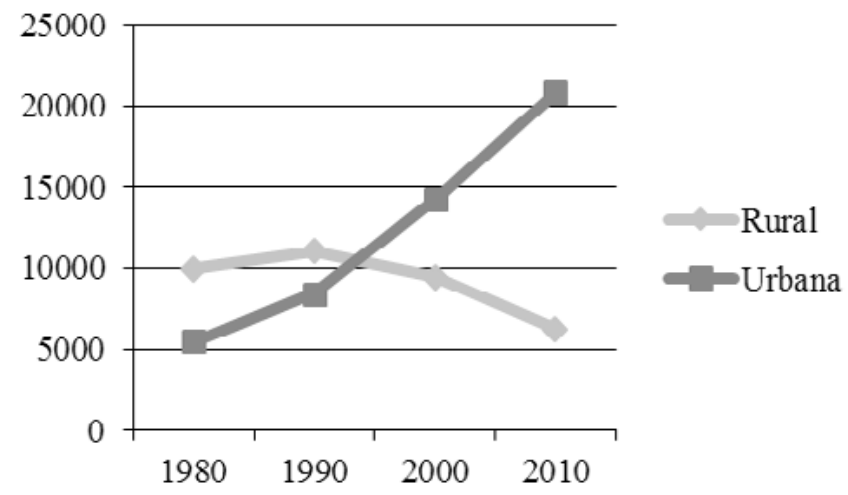

Fonte: As autoras, com base em IBGE (2015).

Além do aumento populacional - de 17.181 habitantes em 1991 para 27.126 em 2010 - houve diminuição dos moradores da Zona Rural e aumento considerável de habitantes na Zona Urbana. 
Essas alterações têm impacto sobre as práticas sociais cotidianas, principalmente aquelas que põem as pessoas em contato e, assim, propiciam que as variantes inovadoras na fala se difundam. É o que parece ter ocorrido em vinte anos na zona urbana de Flores da Cunha, que passou de um pequeno e seguro aglomerado (1990) para um núcleo mais denso, em que as pessoas já não se reconhecem (2008-2009), como evidenciam os trechos de entrevistas sociolinguísticas:

Não tem muitos assaltantes, que nem em certos lugares, que não dá nem pra deixar as portas abertas, digo eu, né. Que às vezes aqui a gente sai e vai ali pra baixo e nem fecha direito as portas e nem as janelas, deixa tudo assim, né. Não é tão perigoso que nem fosse uma cidade grande, né. (VARSUL, FC, inf. 01)

Hoje se você sai aqui, mesmo quando tem um evento, antigamente se conhecia as pessoas mais fácil, hoje tu não conhece mais todo mundo. Existe uma variedade grande de pessoas que até misturou a raça". (BDSer, FC, inf. 195)

Na zona urbana de 1990, o reconhecimento mútuo promovia o uso da fala dialetal italiana até mesmo em estabelecimentos comerciais. Na de 2008-2009, com mais sujeitos e mais demandas sócio-econômicas monolíngues-português, a fala dialetal italiana, reforçadora da lateral alveolar em coda silábica no português de bilíngues, perde espaço. Embora saibam do valor cultural do falar dialetal italiano, os florenses percebem seu declínio cotidiano, como também a tendência ao monolinguismo-português das novas gerações.

Agora eu ali na loja falo muito italiano, porque eu lido muito com o pessoal do interior, né? E geralmente elas chegam, já falam em italiano, né, e eu tenho que falar junto. E tu tem que ter, tem que falar porque daí elas te entendem e te acham simpática, né? Se tu não fala e já começa a tirar de lado, né, elas já não gostam. Então eu falo muito italiano. (VARSUL, FC, inf. 03)

Mas o dialeto já é tradição aqui, a gente alguma coisa, na medida do possível, ainda fala, mas é sempre menos, sempre menos. O pessoal mais de idade que conversa de vez em quando, a gente tá junto e conversa. Com o passar do tempo sempre menos. Pelo menos eu tento ensinar alguma coisa pros meus filhos, mas é muito pouco, eles não têm tanto interesse. Pelo menos eu tento fazer com que eles mantenham a cultura. (BDSer, inf. 190) 


\section{Conclusão}

A análise em tempo real aqui realizada, diferentemente de estudo anterior com dados da mesma fonte, revelou haver vocalização da lateral em coda silábica em Flores da Cunha em 1990, na proporção total de $12 \%$. O processo progrediu na comunidade em vinte anos e, em 2008-2009, atingiu uma proporção relativamente alta, de $77 \%$.

O padrão de vocalização variável da lateral em coda se modificou no período, principalmente no que diz respeito às variáveis linguísticas. O processo é condicionado pelos falantes jovens tanto em 1990 quanto em 2008-2009, mas, em relação à tonicidade da sílaba, as tônicas deixam de ter papel no período mais recente, como também aumentam os efeitos fonotáticos do contexto fonológico seguinte.

Flores da Cunha, a exemplo de outros pequenos municípios brasileiros nascidos dos fluxos imigratórios europeus ao sul do Brasil no final do século XIX, vem vivenciando efeitos de mudanças sócio-econômicas. O exercício da fala faz parte do conjunto de práticas sociais locais. Antes calcadas nas tradições de base étnica italiana, hoje contemplam também valores e elementos supra-locais, como o monolinguismo-português. A vida em núcleos urbanos adensados, a exposição frequente à mídia, as interações diárias no trabalho e nas instituições de ensino, os contatos com membros de outras comunidades de fala aumentam o espaço do português. Por consequência, reduzem-se a prática da fala dialetal italiana e as marcas no português de contato, entre elas a realização consonantal da lateral em coda silábica.

Em tempo real, esta análise mostrou que as mudanças linguísticas acompanharam mudanças na comunidade de fala. Dependentes que somos de informações de outras áreas de conhecimento, talvez não tenhamos estabelecido todas as relações possíveis entre linguagem, sociedade e cultura. Acreditamos, no entanto, ter prestado alguma contribuição ao esclarecimento do padrão de variação e mudança fonéticofonológica do português brasileiro, em uma de suas variedades regionais. 


\section{REFERÊNCIAS}

ASHBY, P. Understanding phonetics. London: Hodder Education, 2011.

BATTISTI, E.; MORAS, V. T. Análise em tempo aparente da vocalização variável da lateral pós-vocálica em Flores da Cunha (RS). Caderno de Letras - UFPEL, n.24, 2015 (no prelo).

BOERSMA, P.; WEENINK, D. Praat: doing phonetics by computer [Computer program]. Versão 5.3.51, 2013. Disponível em: http:// www.praat.org/. Acesso em: 20/07/2013.

CÂMARA JR, J. M. Estrutura da Lingua Portuguesa. 8.ed. Rio de Janeiro: Editora Vozes, 1977.

CARDOSO, S.A.M. da S. et. al. Atlas linguístico do Brasil. Londrina: EDUEL, 2014.

COLLISCHONN, G. Vocalização de L. In: BISOL, L.; BATTISTI, E. (Orgs.). O português falado no Rio Grande do Sul. Porto Alegre: EDIPUCRS, p. 89-104, 2014.

De LACY, P. Markedness: Reduction and preservation in phonology. Cambridge: Cambridge University Press, 2006.

GOLDSMITH, J.A. Autosegmental and metrical phonology. Oxford: Blackwell, 1990.

IBGE - Instituto Brasileiro de Geografia e Estatística. Disponível em: http://cod.ibge.gov.br/233B0. Acesso em: 01/11/2015.

JOHNSON, D. E. Rbrul version 2.3. Out. 2015. Disponível em: http://www.danielezrajohnson.com. Acesso em: 04/11/2015.

LABOV, W. Sociolinguistic patterns. Philadelphia: University of Philadelphia Press, 1972.

LABOV, W. Principles of linguistic change: internal factors. Oxford/Cambridge: Blackwell, 1994.

OLIVEIRA, A. W. Perfil sócio-econômico de Flores da Cunha. Flores da Cunha: Degráfica Impressos, 1992.

PINHO, A. J. de; MARGOTTI, F. W. A variação da lateral pósvocálica /1/ no português do Brasil. Working papers in linguistics, n.2, p.67-88, 2010. 
QUEDNAU, L. A lateral pós-vocálica no português gaúcho: análise variacionista e representação não-linear. Porto Alegre, 1993. Dissertação (Mestrado em Letras (Língua Portuguesa)) Instituto de Letras. Universidade Federal do Rio Grande do Sul, Porto Alegre, 1993.

TASCA, M. A lateral em coda silábica no Sul do Brasil. Porto Alegre, 1999. Tese (Doutorado em Letras (Linguística Aplicada)) Faculdade de Letras. Pontifícia Universidade Católica do Rio Grande do Sul, Porto Alegre, 1999.

\begin{abstract}
Vocalization of the lateral consonant in syllable coda in a variety of Brazilian Portuguese: A real time sociolinguistic analysis
\end{abstract}

The article brings the results of a real-time, variable rule analysis $(L A B O V, 1972,1994)$ of the vocalization of the lateral consonant $M$ in syllable coda (canal cana[w] 'channel', Brasil Brasi[w] 'Brazil') in Brazilian Portuguese in the speech of Flores da Cunha (RS). It shows that from 1990 to 2008-2009 the rule progressed along with social and economic changes verified in that small city, founded in the end of the XIX century by Italian immigrants. Young people favoured the application of the rule, women completed the acquisition of the vocalized form. The tendency to vocalize grew bigger in the presence of high consonants and back vowels, besides labial consonants, in the following phonological context. The stressed syllable ceased to have conditioning effect. The total proportion of rule application went from $12 \%$ in 1990 to $77 \%$ in 2008-2009. The big increase in the proportion of rule application accompanied the growth of the urban population and of the economic activities carried on in the urban area. This reduced the speaking of Italian dialects and their contact with Portuguese, which could have restrained vocalization.

Key words: Language variation, Brazilian Portuguese, Vocalization of the lateral consonant in syllable coda, Real-time analysis. 